\title{
Effects of acute alcohol consumption on cardiac excitation, conduction, and repolarization: results from the Munich Beer Related Electrocardiogram Workup Study (MunichBREW)
}

\author{
Stefan Brunner ${ }^{1}$ (D) $\cdot$ Cathrine Drobesch ${ }^{1} \cdot$ Rebecca Herbel $^{1} \cdot$ Moritz F. Sinner $^{1,2}$
}

Received: 8 February 2021 / Accepted: 5 March 2021 / Published online: 18 March 2021

(c) The Author(s) 2021

Sirs:

Alcohol consumption may result in both deleterious and beneficial cardiovascular effects. Chronic heavy alcohol consumption can lead to systolic and diastolic dysfunction and left ventricular dilatation culminating in severe alcoholic cardiomyopathy [1]. Acute excessive alcohol intake has been repeatedly associated with the 'Holiday Heart Syndrome'. It is characterized by the occurrence of supraventricular and ventricular arrhythmias in otherwise healthy individuals [2]. So far, one of the largest prospective study in this context is the MunichBREW study, investigating over 3000 voluntary participants at the 2015 Munich Octoberfest for cardiac arrhythmias under the influence of acute alcohol exposure. The study demonstrated a clear association of acute alcohol consumption with cardiac arrhythmias and sinus tachycardia in particular. As a potential trigger for cardiac arrhythmias emerged an imbalance of the autonomic nervous system as indicated by a significant reduction of respiratory sinus arrhythmia [3, 4].

In the MunichBREW study, electrocardiograms (ECGs) were analyzed qualitatively only [3]. Importantly, an analysis of quantitative ECG characteristics has not been performed yet. Here, we thus aimed to systematically investigate these quantitative ECG characteristics, representing cardiac excitation, conduction, and repolarization.

The MunichBREW study originally enrolled 3042 voluntary participants. After exclusions, 3,012 of them were included in the present analysis. Participants had to

Stefan Brunner

Stefan.Brunner@med.uni-muenchen.de

1 Department of Medicine I, LMU Klinikum, University Hospital, LMU Munich, Marchioninistr. 15, 81377 Munich, Germany

2 German Centre for Cardiovascular Research (DZHK), Partner Site: Munich Heart Alliance, Munich, Germany be $\geq 18$ years old and provide written informed consent to study inclusion. Four individuals who presented with a breath alcohol concentration $(B A C) \geq 3.00 \mathrm{~g} / \mathrm{kg}$ were excluded due to German law, and 26 individuals had uninterpretable ECGs. The ethics committee at the Ludwig Maximilians University of Munich, Germany approved the study, which was registered at clinicaltrials.org (NCT02550340).

In all study subjects, ECG recordings of $30 \mathrm{~s}$ duration were obtained using the smart phone-based AliveCor device (AliveCor, San Francisco, CA, USA). BAC in gram per kilogram $(\mathrm{g} / \mathrm{kg})$ was determined using a Dräger Alcotest 7510 handheld device (Drägerwerk AG, Lübeck, Germany). Clinical covariates age, sex, country of origin, history of heart disease, use of cardiovascular drugs, use of antiarrhythmic drugs, and active smoking status were collected by questionnaire. Quantitative ECG analysis included heart rate, PR interval, QRS duration, and QTc interval. QTc corrected for residuals of heart rate, age, and sex. All ECGs measurements were performed caliper-based on digital ECG recordings by two experienced cardiologists blinded to BAC and covariates. Results are expressed as mean \pm standard deviation. We employed linear regression to test the association between quantitative ECG measures and BAC, adjusting for clinical covariates. We considered $p<0.05$ statistically significant.

The mean age of the study cohort was $35.0 \pm 13.2$ years. Thirty percent of the participants were female. The participants originated from 60 different countries. The most reported nationalities were German (69\%), US-American (5\%), Austrian (4\%), and Australian (4\%). Six percent reported an underlying heart disease and $3 \%$ reported a known arrhythmia. Six percent used cardiac medication and $29 \%$ were active smokers.

ECG analysis revealed a mean heart rate across all participants of $91.0 \pm 15.7$ beats per minute (bpm) [median (25th; 75th): 90 (80;101) bpm]. Mean PR interval was $135.5 \pm 27.0 \mathrm{~ms}$ [median (25th; 75th): $133(117 ; 151) \mathrm{ms}$ ], mean QRS duration was 115.2 \pm 20.8 ms [median (25th; 
75th): $113(101 ; 127) \mathrm{ms}$ ], and mean QTc interval was $369.0 \pm 24.4 \mathrm{~ms}$ [median (25th; 75th): 368 (354;382) ms].

Regression analysis, adjusted for age, sex, country of origin, prevalent heart disease, known arrhythmias, cardiac medication use, and smoking status, showed a significant association of heart rate with increasing BAC [Beta (standard error (SE)): $5.4(0.51) ; p<0.001]$. There was no significant association of increasing BAC and PR interval [1.8 (0.92); $p=0.84]$, QRS duration [ $0.57(0.73) ; p=0.44]$, and QTc interval [0.67 (0.88); $p=0.45]$ (Fig. 1).

In of one the largest prospective trials on the ECG effects of acute alcohol intake, we could show that quantitatively analyzable ECGs can be successfully obtained under unfavorable recording conditions at the Munich Octoberfest. As the main result, we clearly demonstrate a significant association with increasing heart rate and BAC. There was no association between alcohol and PR interval, QRS duration, and QTc interval.

The adverse cardiovascular effects following acute alcohol consumption may be related to the release of

\section{A}

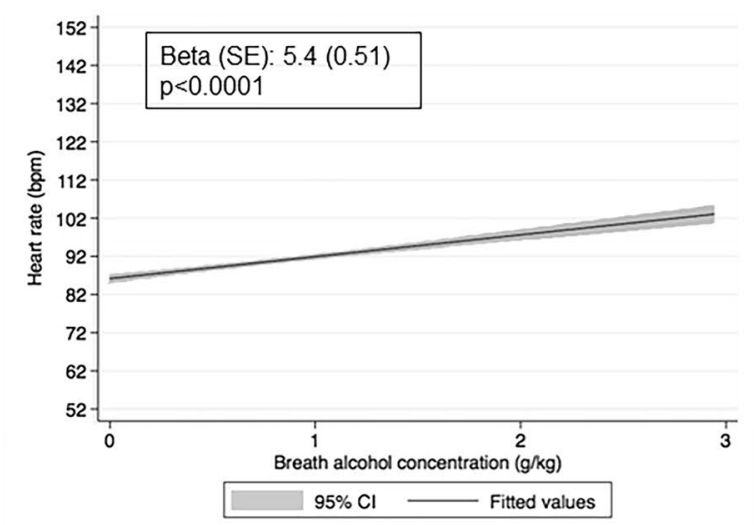

\section{C}

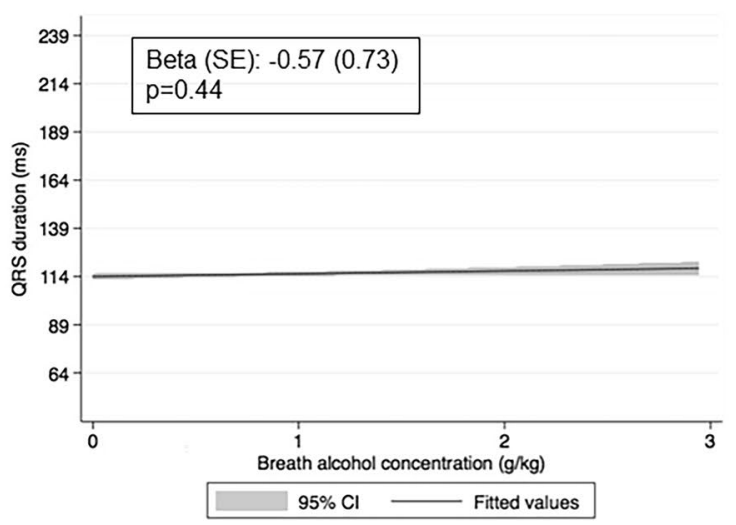

Fig. 1 Regression lines of breath alcohol concentrations with a Heart rate, b PR interval, c QRS duration, and d QTc interval. In each panel, the solid lines illustrate the fitted regression, the shaded areas catecholamines, imbalance of the autonomic nervous system, electrophysiological consequences of alcohol metabolites, and deranged plasma electrolytes. A variety of ECG changes has been described in the setting of acute alcohol intoxication including a new onset of ventricular and atrial arrhythmias, referred to as the 'Holiday Heart Syndrome'. Further, small case series described prolongation of the $\mathrm{PR}, \mathrm{QRS}$, and QT intervals, measures that reflect cardiac excitation, conduction and repolarization. [5-8]

In the previous, prospective MunichBREW trial, we observed a strong association of qualitatively assessed sinus tachycardia with increasing BAC under real-life conditions, which persisted after adjusting for confounders. Our current findings of quantitative analyses of ECG measures further confirm prior studies reporting an increase in heart rate following alcohol intake in experimental settings. The increase in heart rate may reflect an imbalance of the autonomic nervous system resulting from both an increase in sympathetic activity and a decrease of vagal tone $[9,10]$.

B

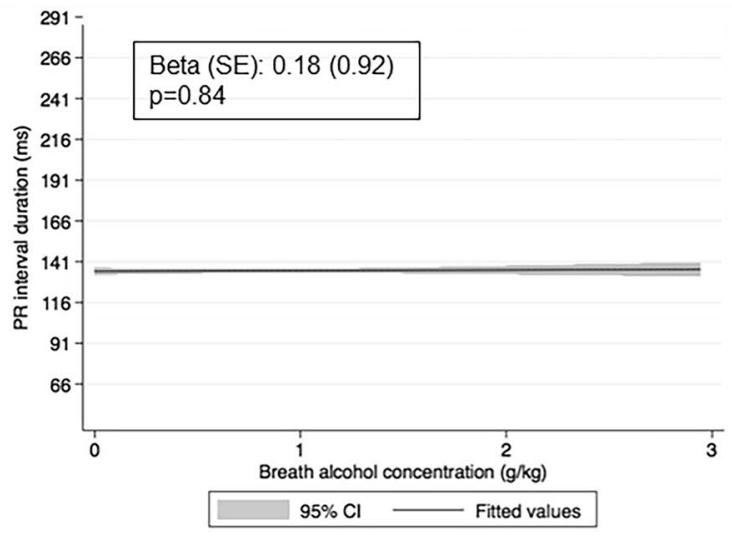

D

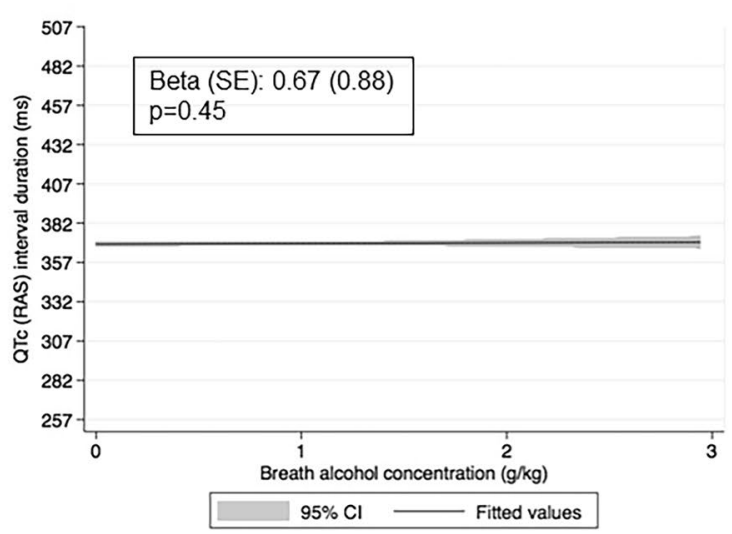

indicate the respective $95 \%$ confidence intervals around the regression lines. Insets report the effect size beta and its standard error (SE). RAS indicates the QT interval is corrected for rate, age, and sex 
However, we did not observe an association of BAC with $\mathrm{PR}, \mathrm{QRS}$, and QTc intervals. This is in contrast to previous reports. Yet as the MunichBREW study is among the largest investigations in this field, it may be inferred that possible alcohol-induced alterations of cardiac conduction and repolarization may not be clinically relevant. In addition, previously reported effects may have been overestimated based on small study sizes. Alternatively, prior cohorts may have had a higher prevalence of underlying conditions, whereas our cohort was relatively young and healthy. An increased sympathetic tone may thus be the primary proarrhythmic mechanism in our cohort.

A number of considerations are warranted. The lively conditions at the Munich Octoberfest may have influenced the results. Particularly, the circumstances have precluded collecting a more detailed history and additional physical or technical evaluations. Further, with a single ECG recording, we cannot elucidate the temporal relation between alcohol consumption and the occurrence of ECG changes.

In conclusion, the so far largest prospective study associating quantitative ECG measures with acute alcohol exposure revealed a strong association between increasing BAC and heart rate. There was no significant association between PR, QRS, and QTc intervals and increasing BAC. Further studies are required to analyze the temporal relation of alcohol consumption and the occurrence of ECG changes.

Acknowledgements We thank the Staatliches Hofbräuhaus in München and its director Dr. Michael Möller for facilitating the conduction of our research. This work is part of the doctoral theses of Rebecca Herbel and Cathrine Drobesch.

Funding Open Access funding enabled and organized by Projekt DEAL. This work was supported by the Stiftung Biomedizinische Alkoholforschung and institutional funds of the Department of Medicine I of the University Hospital Munich. In addition, the project has received funding from the European Commission's Horizon 2020 research and innovation program under grant agreement No 633196.

\section{Declarations}

Conflict of interest All authors have no conflict of interest.

Open Access This article is licensed under a Creative Commons Attribution 4.0 International License, which permits use, sharing, adaptation, distribution and reproduction in any medium or format, as long as you give appropriate credit to the original author(s) and the source, provide a link to the Creative Commons licence, and indicate if changes were made. The images or other third party material in this article are included in the article's Creative Commons licence, unless indicated otherwise in a credit line to the material. If material is not included in the article's Creative Commons licence and your intended use is not permitted by statutory regulation or exceeds the permitted use, you will need to obtain permission directly from the copyright holder. To view a copy of this licence, visit http://creativecommons.org/licenses/by/4.0/.

\section{References}

1. Kupari M, Koskinen P, Suokas A (1991) Left ventricular size, mass and function in relation to the duration and quantity of heavy drinking in alcoholics. Am J Cardiol 67(4):274-279. https://doi. org/10.1016/0002-9149(91)90559-4

2. Ettinger PO, Wu CF, De La Cruz C, Weisse AB, Ahmed SS, Regan TJ (1978) Arrhythmias and the "Holiday Heart": alcoholassociated cardiac rhythm disorders. Am Heart J 95(5):555-562. https://doi.org/10.1016/0002-8703(78)90296-x

3. Brunner S, Herbel R, Drobesch C, Peters A, Massberg S, Kaab S, Sinner MF (2017) Alcohol consumption, sinus tachycardia, and cardiac arrhythmias at the Munich Octoberfest: results from the Munich Beer Related Electrocardiogram Workup Study (MunichBREW). Eur Heart J 38(27):2100-2106. https://doi.org/10.1093/ eurheartj/ehx 156

4. Sinner MF, Brunner S (2017) Arrhythmias at the Munich Octoberfest: ECG under the influence? Eur Heart J 38(35):2641-2643. https://doi.org/10.1093/eurheartj/ehx444

5. Aasebo W, Erikssen J, Jonsbu J, Stavem K (2007) ECG changes in patients with acute ethanol intoxication. Scand Cardiovasc J 41(2):79-84. https://doi.org/10.1080/14017430601091698

6. Cardy MA, Donnerstein RL, Kelly LF, Bittner NH, Palombo GM, Goldberg SJ (1996) Acute effects of ethanol ingestion on signalaveraged electrocardiograms. Am J Cardiol 77(15):1356-1357. https://doi.org/10.1016/s0002-9149(96)00205-6

7. Lorsheyd A, de Lange DW, Hijmering ML, Cramer MJ, van de Wiel A (2005) PR and OTc interval prolongation on the electrocardiogram after binge drinking in healthy individuals. Neth J Med 63(2):59-63

8. Macfarlane PW, Murray H, Sattar N, Stott DJ, Ford I, Buckley B, Jukema JW, Westendorp RG, Shepherd J (2011) The incidence and risk factors for new onset atrial fibrillation in the PROSPER study. Europace 13(5):634-639. https://doi.org/10.1093/europace/ eur016

9. Sagawa Y, Kondo H, Matsubuchi N, Takemura T, Kanayama H, Kaneko Y, Kanbayashi T, Hishikawa Y, Shimizu T (2011) Alcohol has a dose-related effect on parasympathetic nerve activity during sleep. Alcohol Clin Exp Res 35(11):2093-2100. https://doi.org/ 10.1111/j.1530-0277.2011.01558.x

10. Spaak J, Tomlinson G, McGowan CL, Soleas GJ, Morris BL, Picton P, Notarius CF, Floras JS (2010) Dose-related effects of red wine and alcohol on heart rate variability. Am J Physiol Heart Circ Physiol 298(6):H2226-2231. https://doi.org/10.1152/ajphe art.00700.2009 